\section{Contribution of the Pancreas to Circulating Somatostatin-like Immunoreactivity in the Normal Dog}

\author{
Gerald J. Taborsky, Jr. and John W. Ensinck \\ Department of Medicine, University of Washington, Seattle, \\ Washington 98105; Division of Endocrinology and Metabolism, \\ Veterans Administration Medical Center, \\ Seattle, Washington 98108
}

A. sess the contribution of the pancreas to the somatostatinlike immunoreactivity (SLI) circulating in arterial and portal venous plasma. Basal SLI concentrations in arterial, pancreatic venous, and portal venous plasma were $95 \pm 9$, $277 \pm 32$, and $130 \pm 12 \mathrm{pg} / \mathrm{ml}$, ( $\bar{x} \pm S E M)$, respectively. Measurement of pancreatic and portal venous blood flow $(5 \pm 1$ vs. $365 \pm 46 \mathrm{ml} / \mathrm{min})$ and hematocrit allowed calculation of net, base-line SLI output from the right lobe of the pancreas $(521 \pm 104 \mathrm{pg} / \mathrm{min})$ and from the gastrointestinal tract $(8,088 \pm 1,487 \mathrm{pg} / \mathrm{min})$, which suggested that the contribution of the pancreas to circulating SLI was minor when the D cells were not stimulated. To stimulate the secretion of SLI from both pancreatic and nonpancreatic sources, isoproterenol, a beta-adrenergic agonist, was infused intravenously for $1 \mathrm{~h}$ into six anesthetized dogs. Arterial SLI increased by $52 \pm 9 \mathrm{pg} / \mathrm{ml}$; superior pancreatico-duodenal venous SLI increased by $380 \pm 95 \mathrm{pg} / \mathrm{ml}$; portal venous SLI increased by $134 \pm 14$ $\mathrm{pg} / \mathrm{ml}$. Pancreatic venous blood flow remained unchanged at $5 \pm 1 \mathrm{ml} / \mathrm{min}$, but portal venous blood flow increased to $522 \pm 62 \mathrm{ml} / \mathrm{min}$. SLI output from the right lobe of the pancreas increased by $684 \pm 227 \mathrm{pg} / \mathrm{min}$ and that from the gastrointestinal tract increased by $23,911 \pm 3,197 \mathrm{pg} /$ min, again suggesting that the pancreas was a minor source of circulating SLI even when the D cells were stimulated. We conclude that the measurement of arterial-venous SLI concentrations, in the absence of measurements of

Presented in preliminary form at the 41 st Annual Meeting of the American Diabetes Association, Cincinnati, Ohio, June 1981 and at the Second International Symposium on Somatostatin, Athens, Greece, June 1981. Address correspondence to Dr. Gerald J. Taborsky, Jr., VA Medical Center, Seattle, WA 98108.

Received for publication 2 February 1983 and in revised form 15 September 1983.

The Journal of Clinical Investigation, Inc. Volume 73, January 1984, 216-223 organ blood flow, can give a false impression of the organ's contributions of circulating SLI. To verify that the contribution of the pancreas was negligible, six dogs received an acute pancreatectomy and then an intravenous infusion of isoproterenol at the same rate. In these dogs, both the base-line level of SLI in arterial plasma (109 \pm 12 $\mathrm{pg} / \mathrm{ml})$ and the increment during isoproterenol $(56 \pm 8 \mathrm{pg} /$ $\mathrm{ml}$ ) were similar to those of normal dogs. Likewise, in pancreatectomized dogs both the base-line level of SLI in portal venous plasma $(129 \pm 16 \mathrm{pg} / \mathrm{ml})$ and the increment during isoproterenol $(174 \pm 34 \mathrm{pg} / \mathrm{ml})$ were similar to those of normal dogs. We conclude that, in normal dogs, the pancreas makes a negligible contribution to the basal and stimulated level of SLI in arterial and portal venous plasma and therefore that these levels should not be used as an index of secretory activity of the pancreatic $\mathrm{D}$ cells.

\section{Introduction}

Somatostatin-like immunoreactivity (SLI) ${ }^{1}$ is present in high concentrations in the D cells of the pancreatic islet $(1,2)$ and in the venous effluent of the pancreas (3-5). These observations have led to the assumption (5-9) that the pancreas makes a significant contribution to the SLI circulating in peripheral and portal venous plasma. However, the amount of somatostatin actually released from the pancreas appears to be relatively small, at least in vitro $(10,11)$, and the very short half-time of somatostatin in vivo (12-14) suggests that a large output of somatostatin would be necessary to appreciably influence the arterial or portal venous level of SLI. Furthermore, other evidence $(1,3,4,15,16)$ suggests that the gastrointestinal tract contributes significantly to circulating SLI. Therefore, we sought to determine whether or not the pancreas is a major source of the changes of SLI in arterial and portal venous plasma. To address this question, we measured not only the arterial-venous difference

1. Abbreviations used in this paper: CCK-8, cholecystokinin-8; SLI, somatostatin-like immunoreactivity; SPDV, superior pancreatico-duodenal vein. 
of SLI concentration but also the appropriate venous blood flows, which allowed calculation of the output of SLI from the pancreas and gastrointestinal tract both in the basal state and during the stimulation of pancreatic (10) and nonpancreatic (9) $D$ cells by intravenous isoproterenol. From these data and from infusions of synthetic somatostatin-14, we calculated the contribution of the pancreas to arterial SLI. As an independent test of this hypothesis, we compared both the baseline and stimulated levels of SLI in arterial and portal venous plasma with the levels in dogs who had received an acute pancreatectomy.

\section{Methods}

Animals and surgical procedures. Adult dogs of mixed breed weighing 21-34 kg were fasted for $48 \mathrm{~h}$ before surgery. All dogs were anesthetized with pentobarbital sodium $(30 \mathrm{mg} / \mathrm{kg}$ i.v.). Dogs in the first series of experiments (normal dogs) received an extracorporeal blood flow circuit that routed blood from the superior pancreatico-duodenal vein (SPDV) through an electromagnetic flow meter, past a sampling port, and into the portal vein. This blood flow circuit allowed calculation of SLI output directly from the right lobe of the canine pancreas. The surgical procedures involved have been recently described (17). The dogs receiving intraarterial infusions of cholecystokinin-8 (CCK-8) had a small-bore Teflon catheter placed in the superior pancreatico-duodenal artery; this artery supplies the right lobe of the pancreas with blood.

The pancreatic blood flow circuit was not used in the second series of experiments (pancreatectomized dogs). Rather, an acute pancreatectomy was performed to eliminate any contribution of pancreatic SLI to arterial plasma. The pancreatectomy was started immediately after laparotomy. Venous branches draining the splenic (left) lobe and the duodenal (right) lobe of the dog pancreas were ligated and cut. Where the pancreas was closely attached to the duodenum, a clamp was placed on the duodenum and the remaining pancreas was dissected free. After 45-60 min of the surgery, the entire pancreas was removed. We judged the completeness of the pancreatectomy by visually inspecting for any remaining pancreatic tissue and confirmed this by measuring arterial levels of insulin before, during, and after the infusion of the insulin secretagogue, isoproterenol (see Results).

Dogs receiving isoproterenol in the first two series of experiments had been given the surgery necessary to enable us to measure gastrointestinal output of SLI. A 6- or 7-mm i.d. electromagnetic flow probe (Zepeda Instruments, Seattle, WA) was placed around the portal vein proximal to the entrance to the gastro-splenic vein, which is upstream from the entrance of the SPDV. The probe was fitted tightly around the portal vein, as recommended by Jaspan et al. (18), to ensure accurate measurement of portal venous flow. The flow signal was processed by an electromagnetic flow meter (Zepeda Instruments, model SWF-3RD) and the output recorded on a chart recorder. A catheter was inserted into the portal vein and secured by a purse string suture so that its tip lay just downstream from the flow probe. In all dogs, the femoral artery was exposed and cannulated to allow sampling of arterial blood and measurement of blood pressure and heart rate. Also, the femoral vein was exposed and catheterized to allow an infusion of either isoproterenol or somatostatin-14 (a kind gift from Dr. Jean Rivier, Salk Institute, San Diego, CA). A 1-h stabilization period followed the surgery before baseline samples for the experiment were drawn.

Protocols and assays. Four types of experiments were performed The first series assessed the effects of isoproterenol on arterial SLI, SLI output from the right lobe of the canine pancreas, and SLI output from the gastrointestinal tract of normal dogs. Samples of blood from the femoral artery, SPDV, and the portal vein (see above) were drawn during the control period at $-10,-5$, and $0 \mathrm{~min}$ before the start of the hourlong isoproterenol infusion into the femoral vein at $2 \mu \mathrm{g} / \mathrm{min}$. Samples were drawn at $3,5,10,20,30,40,50$, and $60 \mathrm{~min}$ after the start of the infusion and at $5,15,20,45$, and $60 \mathrm{~min}$ after the infusion was discontinued.

A second type of experiment was performed to determine the effect of a constant rate of somatostatin output on arterial SLI. Somatostatin14 was infused intravenously at $55,000 \mathrm{pg} / \mathrm{min}$ for $30 \mathrm{~min}$. Samples of arterial blood were drawn at $-15,-5$, and $0 \mathrm{~min}$ before; at $5,10,20$, and $30 \mathrm{~min}$ during; and at 5,10,15, and $30 \mathrm{~min}$ after the infusion of somatostatin.

A third type of experiment was performed to assess the effect of intraarterial infusion of CCK-8 upon SLI output from the right lobe of the canine pancreas. Samples of blood were drawn from the femoral artery and SPDV at 2.5-15-min intervals before and during the infusion of CCK -8 at $0.5 \mu \mathrm{g} / \mathrm{min}$ for $70 \mathrm{~min}$ into the superior pancreatico-duodenal artery.

The fourth type of experiment assessed the effect of acute pancreatectomy on the increment of arterial SLI, the increment of portal venous SLI, and the increment of gastrointestinal SLI induced by isoproterenol. Samples of blood from the femoral artery and portal vein were drawn at the times listed above.

Blood samples for SLI radioimmunoassay were drawn into a solution of anticoagulants and proteolytic enzyme inhibitors described by de Häen et al. (19). Samples were kept on ice until centrifuged. Plasma was separated at $4^{\circ} \mathrm{C}$ and frozen at $-20^{\circ} \mathrm{C}$ until assay. Levels of SLI were measured in unextracted plasma by radioimmunoassay, which employed an ${ }^{125}$ I-Tyrosine 11 -somatostatin tracer and an antibody (1:105,000 final dilution) that is apparently directed against residues including No. 6 and No. 8 of the somatostatin- 14 molecule. The antibody used also detects somatostatin-28, an $\mathrm{NH}_{2}$-terminally extended form of somatostatin-14, on an equimolar basis and possibly a very large molecular weight interference factor present in unextracted plasma (20) as well (see below and Discussion). Synthetic somatostatin-14 was used as standard. A change of $1.5 \mathrm{pg} /$ tube was detected with $95 \%$ confidence over the $0-40 \mathrm{pg} /$ tube range of the assay, $18 \mathrm{pg} /$ tube displaced $50 \%$ of specific tracer binding. The coefficient of variation within and between assays was $\leq 7 \%(n=10, n=13$, respectively $)$, both at an average arterial plasma level of SLI (11.2 pg/tube) and at an average SPDV plasma level of SLI (18.6 pg/tube). SLI in arterial, portal venous, and pancreatic venous plasma diluted in parallel with the synthetic somatostatin- 14 . Increments of SLI in arterial plasma produced by infusion of exogenous somatostatin-14 were linearly correlated with the infusion rate $(r$ $=+0.95 ; P<0.0005, n=39$ ). Synthetic somatostatin- 14 incubated under the conditions of the assay with both arterial and pancreatic venous plasma was recovered with $89 \pm 3 \%$ and $91 \pm 1 \%$ efficiency, respectively. There was no detectable degradation of the tracer by plasma under the incubation conditions of the assay. Plasma immunoreactive insulin was measured by radioimmunoassay using the double-antibody technique of Morgan and Lazarow (21). Dog insuiin, obtained from Novo Research Institute in Copenhagen, Denmark, was used as a standard. Plasma glucose was estimated by either the ferricyanide method or the glucose oxidase method.

Data analysis. Net SLI output from the right lobe of the dog pancreas was calculated by subtracting the arterial SLI levels from that in the SPDV and multiplying that quantity times the plasma flow through the SPDV. Net SLI output from the gastrointestinal tract was calculated by subtracting the arterial level of SLI from that in the portal vein and 
multiplying the quantity times the plasma flow through the portal vein. These calculations were designed to remove the artifacts potentially induced by the presence of very high molecular weight interference factors in unextracted plasma (20), since these factors would be expected to be present in approximately equal concentrations in both arterial and venous plasma. The changes of arterial SLI, portal venous SLI, and the SLI outputs were calculated by subtracting the average of the values 15,5 , and $0 \mathrm{~min}$ before the infusions to those values at steady state $(40,50$, and $60 \mathrm{~min}$ after the start of the isoproterenol or $50-70 \mathrm{~min}$ after the start of the CCK-8). The responses of arterial and portal venous SLI were expressed as change from basal levels to eliminate the contribution of very large molecular weight, presumably stable, interference factors potentially present in unextracted plasma (20). The change of arterial SLI during somatostatin infusion was calculated by subtracting the average of the values 15,5 , and $0 \mathrm{~min}$ before the infusion from those at steady state $(10,20$, and $30 \mathrm{~min}$ after the start of the infusion). Paired $t$ tests were used to evaluate the statistical significance of these changes. Comparisons between groups of dogs were made with pairedsample $t$ tests. The data are expressed as mean \pm SEM.

\section{Results}

Base-line SLI, insulin, and glucose in normal dogs. The baseline concentrations of SLI in six normal dogs averaged $95 \pm 9$ $\mathrm{pg} / \mathrm{ml}$ in unextracted arterial plasma, which was significantly less than the $277 \pm 32 \mathrm{pg} / \mathrm{ml}$ measured in SPDV plasma $(P<0.05$, $\bar{x} \pm$ SEM). Blood flow in the SPDV averaged $4.7 \pm 0.5 \mathrm{ml} / \mathrm{min}$ during the base-line period. The net output of SLI from the right lobe of the dog pancreas was $521 \pm 104 \mathrm{pg} / \mathrm{min}$ during the base-line period (Table I).

The base-line concentration of insulin in the arterial plasma of six normal dogs averaged $14 \pm 2 \mu \mathrm{U} / \mathrm{ml}$. The base-line concentration of glucose in the same plasma was $106 \pm 6 \mathrm{mg} / \mathrm{dl}$.

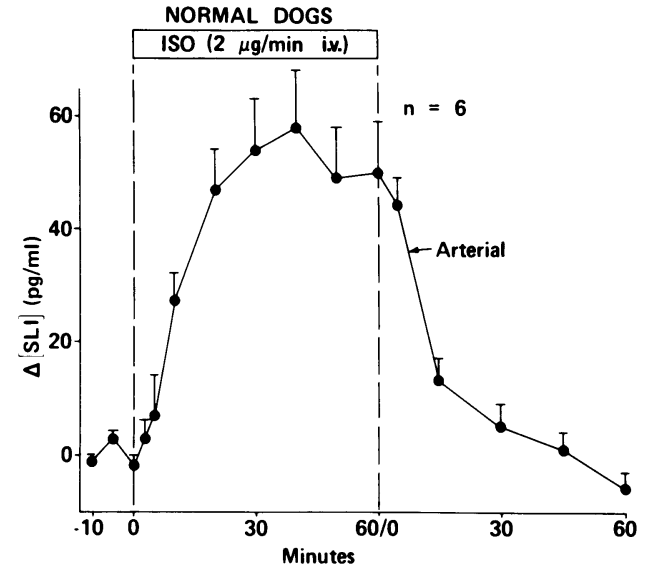

Figure 1. Change $(\Delta)$ from base line of SLI in the arterial plasma of normal, anesthetized dogs before, during, and after the intravenous infusion of isoproterenol (ISO) ( $\bar{x} \pm \mathrm{SEM})$.

Effect of isoproterenol on SLI, insulin, and glucose in normal dogs. Isoproterenol $(2 \mu \mathrm{g} / \mathrm{min}$ i.v. $)$ increased arterial SLI by $52 \pm 9 \mathrm{pg} / \mathrm{ml}(P<0.005)$ after $40-60 \mathrm{~min}$ of the hour-long infusion (Fig. 1). Arterial SLI returned to control levels an hour after the infusion was discontinued (Fig. 1). Isoproterenol also increased arterial insulin levels dramatically by $149 \pm 33 \mu \mathrm{U} / \mathrm{ml}$ $(P<0.005)$ and increased the glucose concentration in arterial plasma marginally by $19 \pm 11 \mathrm{mg} / \mathrm{dl}$. Both insulin and glucose were below control levels $1 \mathrm{~h}$ after the infusion was discontinued.

SLI in SPDV plasma increased by $380 \pm 95 \mathrm{pg} / \mathrm{ml}(P<0.01)$ after 40-60 min of the hour-long isoproterenol infusion. SPDV SLI returned toward control levels by an hour after the infusion

Table I. Venous-Arterial Differences of SLI, Venous Blood Flows, and SLI Outputs during Base Line or Isoproterenol in Normal Dogs

\begin{tabular}{|c|c|c|c|c|c|c|}
\hline & \multicolumn{3}{|c|}{ [SLI] } & \multirow[b]{2}{*}{ 1-hematocrit } & \multirow{2}{*}{$\begin{array}{l}\text { Flow } \\
\text { (SPDV) }\end{array}$} & \multirow{2}{*}{$\begin{array}{l}\text { SLI output } \\
\text { (pancreatic) }\end{array}$} \\
\hline & Arterial & SPDV & V-A & & & \\
\hline & \multicolumn{4}{|c|}{$p g / m l$} & $\mathrm{ml} / \mathrm{min}$ & $p g / m i n$ \\
\hline \multicolumn{7}{|l|}{ Pancreas } \\
\hline Base line & $95 \pm 9$ & $277 \pm 32$ & $184 \pm 30$ & $60 \pm 1$ & $4.7 \pm 0.5$ & $521 \pm 104$ \\
\hline Iso. inf. & $147 \pm 15$ & $657 \pm 112$ & $510 \pm 107$ & $52 \pm 2$ & $4.5 \pm 0.6$ & $1,204 \pm 318$ \\
\hline \multirow[t]{4}{*}{$\Delta$} & $52 \pm 9$ & $380 \pm 98$ & $328 \pm 90$ & - & - & $684 \pm 227$ \\
\hline & \multicolumn{3}{|c|}{ [SLI] } & & & \\
\hline & Arterial & PV & V-A & I-hematocrit & $\begin{array}{l}\text { Flow } \\
\text { (PV) }\end{array}$ & $\begin{array}{l}\text { SLI output } \\
\text { (GI) }\end{array}$ \\
\hline & \multicolumn{4}{|c|}{$p g / m l$} & $\mathrm{ml} / \mathrm{min}$ & $p g / \min$ \\
\hline \multicolumn{7}{|c|}{ Gastrointestinal tract } \\
\hline Base line & $95 \pm 9$ & $130 \pm 12$ & $36 \pm 4$ & $60 \pm 1$ & $365 \pm 46$ & $8,088 \pm 1,487$ \\
\hline Iso. inf. & $147 \pm 15$ & $265 \pm 23$ & $118 \pm 9$ & $52 \pm 2$ & $522 \pm 62$ & $31,999 \pm 434$ \\
\hline$\Delta$ & $52 \pm 9$ & $134 \pm 15$ & $82 \pm 8$ & - & - & $23,911 \pm 3,197$ \\
\hline
\end{tabular}

GI, gastrointestinal; ISO, isoproterenol; PV, portal venous; V-A, venous-arterial. 


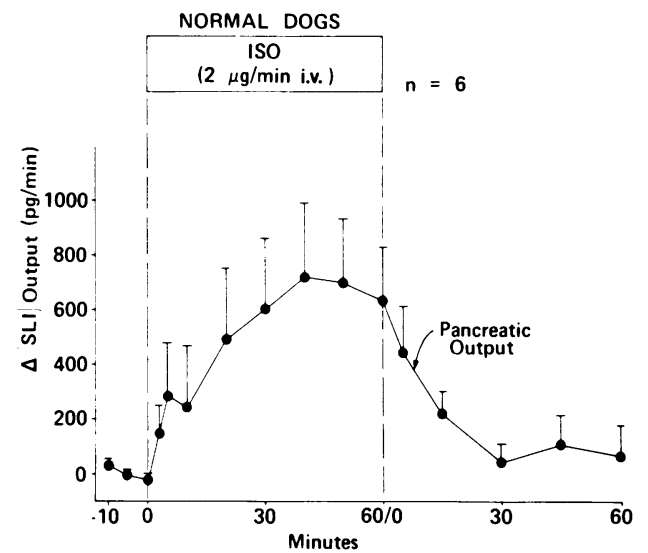

Figure 2. Change $(\Delta)$ from base line of net output of SLI from the right lobe of the dog pancreas before, during, and after the intravenous infusion of ISO into normal anesthetized dogs $(\bar{x} \pm$ SEM).

was discontinued. Blood flow in the SPDV increased transiently during the first $5 \mathrm{~min}$ of the isoproterenol infusion and then returned to control levels despite continuation of the isoproterenol. After 40-60 min of the isoproterenol infusion, output of SLI had increased $(P<0.025)$ by $684 \pm 227 \mathrm{pg} / \mathrm{min}$ (Fig. 2 and Table I). The SLI output returned to control levels by an hour after the infusion of isoproterenol (Fig. 2).

Effect of somatostatin infusion on arterial SLI. To estimate the output of somatostatin needed to account for the increment of arterial SLI observed during isoproterenol (see Discussion), exogenous somatostatin-14 was infused intravenously and the increment of arterial SLI was measured. Somatostatin-14 infused intravenously at $55,000 \mathrm{pg} / \mathrm{min}$ for $0.5 \mathrm{~h}$ produced an increment of SLI in arterial plasma of $42 \pm 5 \mathrm{pg} / \mathrm{ml}(n=11, P<0.0005$, see Fig. 3), which was slightly less than that increment achieved $(52 \pm 9 \mathrm{pg} / \mathrm{ml})$ during isoproterenol.

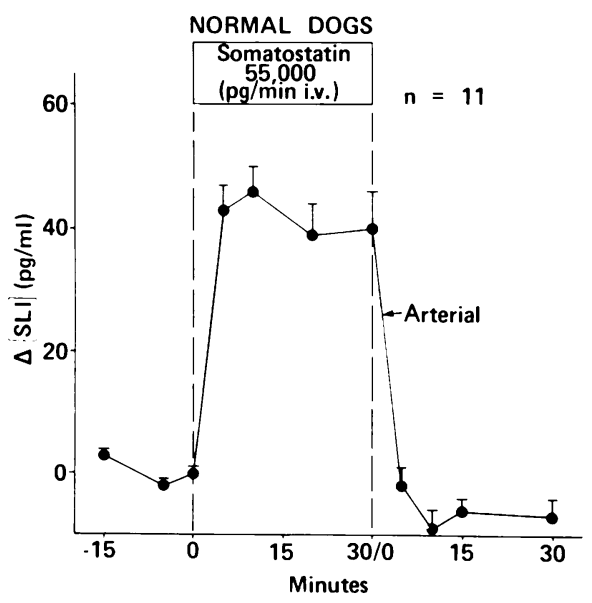

Figure 3. Change $(\Delta)$ from base line of SLI in the arterial plasma of normal dogs before, during, and after the intravenous infusion of somatostatin-14 ( $\bar{x} \pm$ SEM).
Effect of CCK-8 on pancreatic output of SLI. To determine if another stimulus, beside isoproterenol, might produce a larger increase of pancreatic output, CCK-8 was infused directly into the superior pancreatico-duodenal artery for $70 \mathrm{~min}$ at $0.5 \mu \mathrm{g} /$ min. The net output of SLI from the right lobe of the dog pancreas during the base-line period was $481 \pm 105 \mathrm{pg} / \mathrm{min}$, which was not significantly different from that observed before isoproterenol. After 50-70 min of the intraarterial CCK-8 infusion, the output of SLI had increased $(P<0.01)$ by $550 \pm 168 \mathrm{pg} /$ $\mathrm{min}$. The increment during CCK-8 was not significantly different from that during isoproterenol.

Effect of pancreatectomy on SLI, insulin, and glucose. To assess the contribution of the pancreas by an alternative method, the base-line and stimulated levels of SLI in the arterial plasma of normal dogs were compared with those of dogs in whom the pancreas was resected. The base-line concentration of SLI in arterial plasma of six acutely pancreatectomized dogs averaged $109 \pm 12 \mathrm{pg} / \mathrm{ml}$, which was not significantly different from that in normal dogs. Intravenous isoproterenol $(2 \mu \mathrm{g} / \mathrm{min} \times 60 \mathrm{~min})$ increased arterial SLI by $56 \pm 8 \mathrm{pg} / \mathrm{ml}(P<0.005$, see Fig. 4 , open triangles and dashed lines). This increment of arterial SLI in pancreatectomized dogs was not significantly different from that produced by the infusion of isoproterenol in normal dogs (52 $\pm 9 \mathrm{pg} / \mathrm{ml}$, see Fig. 4).

In addition, the portal venous levels of SLI in normal and acutely pancreatectomized dogs were compared. The base-line concentrations of SLI in the portal venous plasma of six normal dogs averaged $130 \pm 12 \mathrm{pg} / \mathrm{ml}$. The increment produced by isoproterenol was $134 \pm 15 \mathrm{pg} / \mathrm{ml}$. The base-line concentration of SLI in portal venous plasma of acutely pancreatectomized dogs averaged $129 \pm 16 \mathrm{pg} / \mathrm{ml}$, not significantly different from that in normal dogs. Infusion of isoproterenol $(2 \mu \mathrm{g} / \mathrm{min} \times 60 \mathrm{~min}$ i.v.) increased portal venous SLI in pancreatectomized dogs by $174 \pm 34 \mathrm{pg} / \mathrm{ml}(P<0.005$, see Fig. 5 , open triangles and dashed lines). This increment of portal venous SLI in pancreatectomized

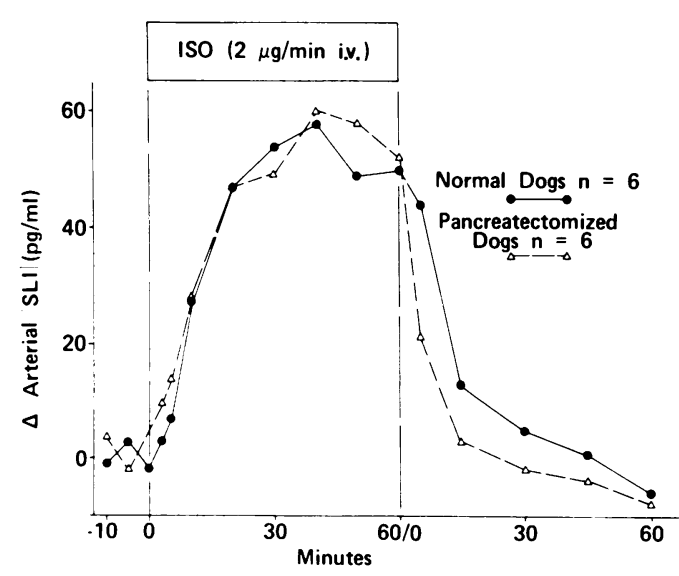

Figure 4. Change $(\Delta)$ from base line of SLI in the arterial plasma of acutely pancreatectomized dogs $(\Delta)$ and normal dogs $(\bullet)$ before, during, and after infusion of ISO ( $\bar{x}$, SEM bars omitted for clarity). 


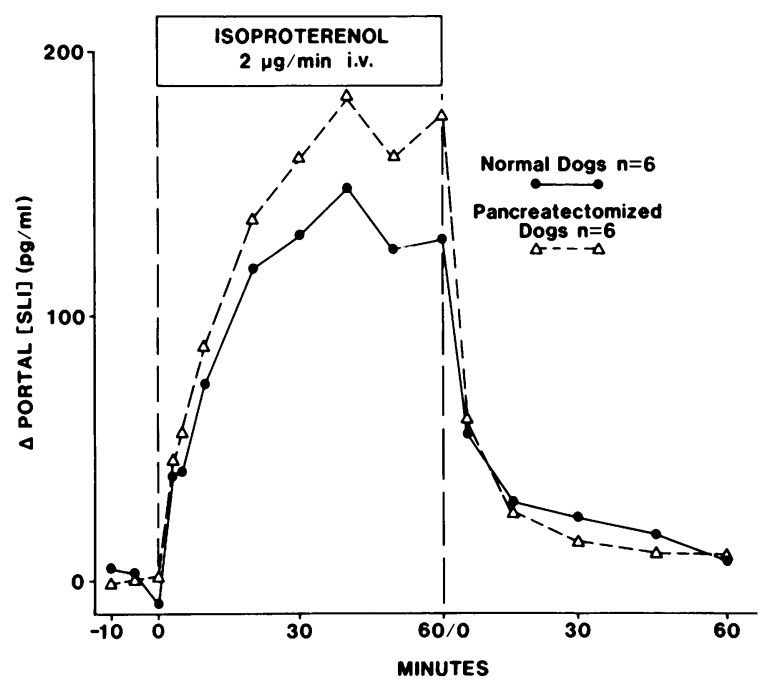

Figure 5. Change $(\Delta)$ from base line of SLI in the portal venous plasma of acutely pancreatectomized dogs $(\Delta)$ and normal dogs $(\bullet)$ before, during, and after the intravenous infusion of isoproterenol $(\bar{x}$, SEM bars omitted for clarity; responses to ISO are not significantly different).

dogs was not significantly different from that produced by the infusion of isoproterenol in normal dogs (Fig. 5).

Base-line concentrations of insulin in the acutely pancreatectomized dogs averaged $0.2 \pm 0.1 \mu \mathrm{U} / \mathrm{ml}$ and did not change significantly $(\Delta=+0.1 \pm 0.1 \mu \mathrm{U} / \mathrm{ml})$ during the isoproterenol infusion. Base-line concentrations of glucose averaged $218 \pm 28$ $\mathrm{mg} / \mathrm{dl}$ and increased dramatically $(\Delta=+107 \pm 23 \mathrm{mg} / \mathrm{dl} ; P$ $<0.005$ ) during the isoproterenol infusion. The base-line concentration of glucose in arterial plasma and the increment observed during the last $20 \mathrm{~min}$ of isoproterenol infusion were both significantly greater in the acutely pancreatectomized dogs $(P<0.005)$.

Gastrointestinal output of SLI. The output of SLI from the gastrointestinal tracts of normal and acutely pancreatectomized dogs was also measured. During the base-line period, the concentration of SLI in portal venous plasma was $130 \pm 12$ $\mathrm{pg} / \mathrm{ml}$; blood flow in the portal vein was $365 \pm 46 \mathrm{ml} / \mathrm{min}$, or $\sim 75$ times that in the SPDV; and the output of SLI from the gastrointestinal tract was $8,088 \pm 1,487 \mathrm{pg} / \mathrm{min}$. During the infusion of isoproterenol portal venous SLI increased by $134 \pm 15$ $\mathrm{pg} / \mathrm{ml}$. Portal vein blood flow peaked during the first $3 \mathrm{~min}$ of the isoproterenol infusion at $685 \pm 95 \mathrm{ml} / \mathrm{min}$ and then plateaued at a level $159 \pm 52 \mathrm{ml} / \mathrm{min}$ above base line $(P<0.025)$ during the last $20 \mathrm{~min}$ of the isoproterenol infusion. During the infusion of isoproterenol, the output of SLI from the gastrointestinal tract of normal dogs increased by $23,911 \pm 3,197 \mathrm{pg} / \mathrm{min}(P$ $<0.0005$, see Fig. 6 and Table I).

In acutely pancreatectomized dogs, portal venous SLI averaged $129 \pm 16 \mathrm{pg} / \mathrm{ml}$ during the base-line period and increased by $174 \pm 34 \mathrm{pg} / \mathrm{ml}$ during the infusion of isoproterenol. Portal vein blood flow averaged $431 \pm 52 \mathrm{ml} / \mathrm{min}$ during the base-line

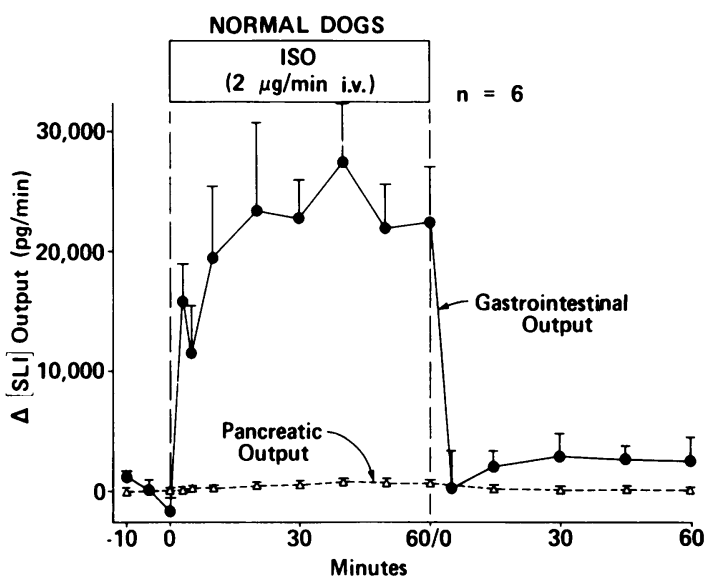

Figure 6. Change $(\Delta)$ from base line of the output of SLI from the gastrointestinal tract $(\bullet)$ and from the right lobe of the dog pancreas $(\Delta)$ before, during, and after the intravenous infusion of ISO in normal dogs.

period and again peaked at $641 \pm 77 \mathrm{ml} / \mathrm{min} 3 \mathrm{~min}$ after the start of the infusion. Portal vein blood flow plateaued at a level $78 \pm 36 \mathrm{ml} / \mathrm{min}$ above $(P<0.05)$ base line during the last 20 $\mathrm{min}$ of the isoproterenol infusion. Base-line output of SLI from the gastrointestinal tract of acutely pancreatectomized dogs was $4,810 \pm 1,764 \mathrm{pg} / \mathrm{min}$, not significantly different from the baseline output of gastrointestinal SLI in normal dogs. During the infusion of isoproterenol, SLI output from the gastrointestinal tract increased by $30,326 \pm 6,398 \mathrm{pg} / \mathrm{min}(P<0.005)$. The increase of SLI output from the gastrointestinal tract in the acutely pancreatectomized dogs was not significantly different from that observed in normal dogs.

\section{Discussion}

The present studies were performed to assess the contribution of the pancreas to the SLI circulating in arterial and portal venous plasma. In the basal state, when the pancreatic D cells were not stimulated by exogenous secretagogues, the arteriovenous difference across the right lobe of the dog pancreas was $184 \pm 30 \mathrm{pg} / \mathrm{ml}$, yet the net SLI output was only $521 \pm 104 \mathrm{pg} /$ min because the measured pancreatic blood flow was small $(5 \pm 1$ $\mathrm{ml} / \mathrm{min}$ ). In contrast, the arterio-venous difference across the gastrointestinal tract was only $36 \pm 4 \mathrm{pg} / \mathrm{ml}$, yet the net output of SLI was $8,088 \pm 1,487 \mathrm{pg} / \mathrm{min}$ because measured portal venous blood flow was large $(365 \pm 46 \mathrm{ml} / \mathrm{min})$. Thus, measurements of arterio-venous differences alone could obscure the fact that the contribution of the pancreas to the SLI circulating in arterial and portal venous plasma is minor when the D cells are not stimulated.

To determine if the contribution of pancreas remains minor when D cell activity is increased, the beta-adrenergic agonist, isoproterenol, was infused to stimulate pancreatic SLI secretion (10). Then, the contribution of that increment of pancreatic 
SLI output to the increment of arterial SLI (22) was calculated. SLI output from the right lobe of the pancreas increased by $684 \pm 227 \mathrm{pg} / \mathrm{min}$ during isoproterenol; however, this value underestimates the total output of SLI from the pancreas, because the SPDV drains only one-half to one-third of the whole pancreas (23). Thus, the increment of total pancreatic SLI output could be as much as $2,000 \mathrm{pg} / \mathrm{min}$. Since the liver extracts $30 \%$ of somatostatin in one pass $(14,24,25)$, the total pancreatic output could be reduced to $1,400 \mathrm{pg} / \mathrm{min}$ by the time it entered the systemic circulation. To determine the posthepatic somatostatin output necessary to produce the $52 \pm 9 \mathrm{pg} / \mathrm{ml}$ increment of arterial SLI observed during isoproterenol infusion, we infused exogenous somatostatin-14 intravenously. Infusion of $55,000 \mathrm{pg} /$ min increased arterial SLI by $42 \pm 5 \mathrm{pg} / \mathrm{ml}$. We have previously shown that the increment of arterial SLI is linearly correlated with the rate of exogenous somatostatin infused (26), and we could therefore estimate that an infusion of $68,000 \mathrm{pg} / \mathrm{min}$ would be necessary to exactly mimic the response of arterial SLI to isoproterenol. Thus, we calculate the contribution of the pancreas as $1,400 \mathrm{pg} / \mathrm{min}$, or $<3 \%$ of the $68,000 \mathrm{pg} / \mathrm{min}$ needed to account for the increase of arterial SLI induced by isoproterenol.

This estimate of the contribution of the pancreas to changes of arterial SLI depends on two major assumptions. First, it is assumed that the SLI output from the whole pancreas could be as much as three times that measured in the effluent of the right lobe of the pancreas. This assumption seems reasonable since the SPDV drains one-half to one-third of the total pancreas (23) and since the distribution of somatostatin throughout the pancreas is relatively homogeneous (27) (it does not display the marked heterogeneity characteristic of glucagon or pancreatic polypeptide [28]). Second, it is assumed that the increase of pancreatic SLI output during isoproterenol is due primarily to an increase in the secretion of somatostatin-14 and therefore that an infusion of exogenous somatostatin- 14 can be used to estimate the pancreatic output necessary to account for the change in arterial SLI. This assumption is not made for gastrointestinal output, since the SLI in the gastrointestinal tract and portal venous plasma contains peptides similar to both somatostatin-14 and somatostatin-28 $(15,16)$. Somatostatin- 14 does appear to be the predominant form of SLI found in (15, 16) and synthesized by (29) the pancreas, although recent studies (30) suggest that a small percentage of the SLI found in the SPDV plasma has a molecular weight similar to somatostatin28. Furthermore, the influence of interference factors potentially present in unextracted plasma (20) on the calculated output of pancreatic somatostatin is probably eliminated by using net output (venous-arterial SLI times plasma flow). This assumption also appears reasonable since the interference factors are alphaand beta-globulins (20), which would be present in similar concentrations in both arterial and venous plasma.

Because our estimates of the contribution of the pancreas depend on the validity of the assumptions listed above, we sought to verify that the pancreas makes a negligible contribution to arterial and portal venous SLI by a totally independent experimental method. Therefore, a series of dogs underwent pan- createctomy and shortly thereafter received an infusion of the same dose of isoproterenol used in the normal dogs. Pancreatectomy changed neither the base-line levels of arterial SLI nor the increment of arterial SLI during isoproterenol. Likewise, pancreatectomy changed neither the base-line levels of portal venous SLI nor the increment of portal venous SLI during isoproterenol. Thus, it appears from this series of studies as well that the pancreas makes a negligible contribution to either arterial or portal venous SLI. These conclusions agree with those of Marre et al. (31), whose preliminary data suggest that the stomach, rather than the pancreas, is responsible for the SLI response to arginine in the portal venous plasma of the rat.

It is possible that pancreatectomy could produce compensatory hypersecretion of SLI from nonpancreatic sources and thus obscure the effect of eliminating the contribution of pancreatic D cells to circulating SLI. Indeed, there are reports that insulin deficiency augments SLI output from the stomach (32, 33), and there is a tendency in the present experiments for both the portal venous concentration of SLI and the gastrointestinal output of SLI to be higher in the pancreatectomized dogs than in normal dogs, although neither tendency is statistically significant. However, even if the stimulated gastrointestinal output was truly increased by $25 \%$ after pancreatectomy, this increment appears more than sufficient to replace the contribution of the pancreas. Thus, the contribution of the pancreas to arterial and portal venous SLI again appears minor when compared with that of the gastrointestinal tract.

Others have concluded that the pancreas is a major contributor to circulating SLI $(5-8,34)$. Three major differences between the experimental design of those studies and ours might account for the difference in conclusions. First, although SLI concentrations were measured in pancreatic, gastric, and peripheral veins, appropriate venous blood flows were not measured. With measurements of only SLI concentration in the venous effluent of the SLI secreting organs, one could obtain a misleading picture of the organ's contribution to total SLI output. For example, in the present study the increment of SLI concentration during isoproterenol in the SPDV of normal dogs was $\sim 380 \mathrm{pg} / \mathrm{ml}$, whereas the increment of SLI concentration in the portal venous plasma was only $134 \mathrm{pg} / \mathrm{ml}$. However, the blood flow measured in those two veins during isoproterenol infusion was $4.5 \mathrm{ml} / \mathrm{min}$ vs. $522 \mathrm{ml} / \mathrm{min}$, respectively. Thus, the output of SLI from the gastrointestinal tract far exceeds that from the right lobe of the pancreas (Fig. 6), even though the concentration of SLI in the portal venous plasma was lower. Thus, measuring the flow of the venous effluent from the SLI secreting organ is critical to quantifying the contribution of that organ to the level of SLI circulating in arterial and portal venous plasma. Second, the stimulus for SLI secretion differed. We chose isoproterenol as a stimulus of SLI secretion because it is known to stimulate pancreatic SLI secretion (10) and because at the rates used in the present study, it produced an increment of pancreatic SLI similar to that produced by intraarterial infusions of CCK-8 (see Results), a potent secretagogue of pancreatic SLI (35). Nevertheless, it is possible that another secre- 
tagogue could stimulate pancreatic SLI secretion so potently and selectively that the pancreas could make a small contribution to circulating SLI. Third, others have assessed the contribution of the pancreas either after chronic insulin deficiency $(5-7,34)$ or after chronic pancreatectomy (8). Chronic insulin deficiency may produce a hyperplasia of islet $\mathrm{D}$ cells $(36,37)$ and hypersecretion of pancreatic SLI $(36,38,39)$, leading one to overestimate the contribution of pancreatic SLI in normal dogs. Alternatively, long standing deficiency of exocrine pancreatic function might be expected to alter meal patterns and nutrient absorption which, in turn, might diminish the stimulation for SLI output from the D cells of the gastrointestinal tract. Indeed, Schusdziarra et al. (8) noted that the SLI response to intragastric casein hydrolysate was decreased in the venous effluent of the gastric fundus. Thus, chronic manipulations may either augment or decrease the normal rate of SLI secretion, making it difficult to gauge the contribution of various organs to the SLI circulating in peripheral or portal venous plasma of the normal animal.

In summary, the results presented suggest that SLI output from the pancreas makes a negligible contribution to the SLI circulating in either arterial or portal venous plasma. These conclusions imply that changes in the level of SLI in systemic or portal venous plasma should not be used as an index of the secretory activity of the pancreatic D cells. We suggest that measurement of at least SLI concentration in pancreatic venous plasma is required to document changes of pancreatic D cell activity. The failure of the pancreas to significantly alter the levels of SLI in peripheral or portal venous plasma coupled with the recent suggestion $(26,40)$ that the pancreas may actually extract a large percentage of the somatostatin secreted from the islet $\mathrm{D}$ cells seems to rule out the possibility of a significant extrapancreatic role for pancreatic somatostatin. The remaining possibilities include a paracrine or local inhibitory action on the neighboring islet A and B cells or a local inhibitory effect on the acinar cells of the exocrine pancreas (41), some of which are downstream from the venous effluent of the islet $D$ cells $(42,43)$. Either of these intrapancreatic actions of pancreatic somatostatin could influence the processing and disposal of ingested nutrients.

\section{Acknowledgments}

The authors thank Dr. Daniel Porte, Jr., for scientific advice; Dr. Thomas L. Paquette for advice on radioimmunoassay; Scott Horton, Barbara O'Neill, Peter Havel, Connie Holmes, Sue Soper, and Andy Reenan for technical assitance; and Louise Parry, Anne Bartlett, Patricia Jenkins, and Maxine Cormier for secretarial assistance.

These studies were supported in part by the Veterans Administration, U. S. Public Health Service grants AM-12829, AM-17047, AM-16008, AM-02456, and RR-37.

\section{References}

1. Arimura, A., S. Haruko, A. Dupont, N. Nishi, and A. V. Schally. 1975. Somatostatin: abundance of immunoreactive hormone in rat stomach and pancreas. Science (Wash. DC). 189:1007-1009.
2. Dubois, M. P. 1975. Immunoreactive somatostatin is present in discrete cells of the endocrine pancreas. Proc. Natl. Acad. Sci. USA. 72:1340-1343.

3. Schusdziarra, V., V. Harris, J. M. Conlon, A. Arimura, and R. Unger. 1978. Pancreatic and gastic somatostatin release in response to intragastric and intraduodenal nutrients and $\mathrm{HCL}$ in the dog. J. Clin. Invest. 62:509-518.

4. Schusdziarra, V., D. Rouiller, A. Pietri, V. Harris, E. Zyznar, J. M. Conlon, and R. H. Unger. 1979. Pancreatic and gastric release of somatostatin-like immunoreactivity during intestinal phase of a meal. Am. J. Physiol. 237:E555-E560.

5. Schusdziarra, V., R. E. Dobbs, V. Harris, and R. H. Unger. 1977. Immunoreactive somatostatin levels in plasma of normal and alloxan diabetic dogs. FEBS (Fed. Eur. Biochem. Soc.) Lett. 81:69-72.

6. Schusdziarra, V., D. Rouiller, V. Harris, and R. H. Unger. 1981. Origin of peripheral venous hypersomatostatinemia in alloxan-diabetic dogs. Endocrinology. 109:1107-1110.

7. Patel, Y. C., T. Wheatley, and H. H. Zingg. 1980. Increased blood somatostatin concentration in streptozotocin diabetic rats. Life Sci. 27:1563-1570.

8. Schusdziarra, V., D. Rouiller, V. Harris, and R. H. Unger. 1979. Plasma somatostatin-like immunoreactivity in depancreatized dogs. Endocrinology. 105:595-599.

9. Koop, H., I. Behrens, C. H. S. McIntosh, R. A. Pederson, R. Arnold, and W. Creutzfeldt. Adrenergic modulation of gastric somatostatin release in rats. FEBS (Fed. Eur. Biochem. Soc.) Lett. 118:248250.

10. Samols, E., and G. C. Weir. 1979. Adrenergic modulation of pancreatic $\mathrm{A}, \mathrm{B}$, and D cells. $\alpha$-adrenergic suppression and $\beta$-adrenergic stimulation of somatostatin secretion, $\alpha$-adrenergic stimulation of glucagon secretion in the perfused dog pancreas. J. Clin. Invest. 63:230238 .

11. Hermansen, K. 1981. Characterisation of the abnormal pancreatic $\mathrm{D}$ and $\mathrm{A}$ cell function in streptozotocin diabetic dogs: studies with D-glyceraldehyde, dihydroxyacetone, D-mannoheptulose, D-glucose, and L-arginine. Diabetologia. 21:489-494.

12. Schusdziarra, V., V. Harris, and R. H. Unger. 1979. Half-life of somatostatin-like immunoreactivity in canine plasma. Endocrinology. 104:109-110.

13. Seal, A., T. Yamada, H. Debas, J. Hollinshead, B. Osadchey, G. Aponte, and J. Walsh. 1982. Am. J. Physiol. 243:G97-G102.

14. Chayvialle, J. A., P. L. Rayford, and J. C. Thompson. 1981. Radioimmunoassay study of hepatic clearance and disappearance halftime of somatostatin and vasoactive intestinal peptide in dogs. Gut. 22:732-737.

15. Trent, D. F., and G. C. Weir. 1981. Heterogeneity of somatostatin-like peptides in rat brain, pancreas, and gastrointestinal tract. Endocrinology. 108:2033-2038.

16. Patel, Y. C., T. Wheatley, and C. Ning. 1981. Multiple forms of immunoreactive somatostatin: comparison of distribution in neural and nonneural tissues and portal plasma of the rat. Endocrinology. 109:1943-1949.

17. Taborsky, G. J., Jr., P. H. Smith, and D. Porte, Jr. 1979. Differential effects of somatostatin analogues on $\alpha$ - and $\beta$-cells of the pancreas. Am. J. Physiol. 236:E123-E128.

18. Jaspan, J., K. Polonsky, M. Lewis, and A. R. Moossa. 1979. Reduction in portal vein blood flow by somatostatin. Diabetes. 28:888892.

19. De Haën, C., S. A. Little, J. M. May, and R. H. Williams. 1978. 
Characterization of proinsulin-insulin intermediates in human plasma. J. Clin. Invest. 62:727-737.

20. Conlon, J. M., M. Bridgeman, and K. G. M. M. Alberti. 1982. The nature of big plasma somatostatin: implications for the measurement of somatostatin-like immunoreactivity in human plasma. Anal. Biochem. 125:243-252.

21. Morgan, C. R., and A. Lazarow. 1963. Immunoassay of insulin: two antibody system. Plasma insulin levels of normal, subdiabetic and diabetic rats. Diabetes. 12:115-126.

22. Boden, G., R. W. Master, M. A. Sattler, J. S. Martin, M. F. Tansy, and O. E. Owen. 1982. Adrenergic control of somatostatin release. Endocrinology. 111:1166-1172.

23. Porte, D., Jr., L. Girardier, J. Seydoux, Y. Kanazawa, and J. Posternak. 1973. Neural regulation of insulin secretion in the dog. $J$. Clin. Invest. 52:210-214.

24. Sacks, H., and L. C. Terry. 1981. Clearance of immunoreactive somatostatin by perfused rat liver. J. Clin. Invest. 67:419-429.

25. Polonsky, K. S., J. B. Jaspan, M. Berelowitz, D. S. Emmanouel, J. Dhorajiwala, and A. R. Moossa. 1981. Hepatic and renal metabolism of somatostatin-like immunoreactivity: simultaneous assessment in the dog. J. Clin. Invest. 68:1149-1157.

26. Taborsky, G. J., Jr., and J. W. Ensinck. 1983. Extraction of somatostatin by the pancreas. Endocrinology. 112:303-307.

27. McIntosh, C., R. Arnold, E. Bothe, H. Becker, J. Kobberling, and W. Creutzfeldt. 1978. Gastrointestinal somatostatin: extraction and radioimmunoassay in different species. Gut. 19:655-663.

28. Gersell, D. J., R. L. Gingerich, and M. H. Greider. 1979. Regional distribution and concentration of pancreatic polypeptide in the human and canine pancreas. Diabetes. 28:11-15.

29. Noe, B. D. 1981. Synthesis of one form of pancreatic islet somatostatin predominates. J. Biol. Chem. 256:9397-9400.

30. Shoelson, S., K. Polonsky, H. Docherty, J. Jaspan, and A. Rubenstein. 1982. Evidence for the presence of somatostatin 28 in plasma. Diabetes. 31:474-477.

31. Marre, M., J. R. Attali, J. Miller, S. Kronheim, and R. Assan. 1981. Respective contributions of pancreas and stomach to rat portal somatostatin-like-immunoreactivity (SLI): an in vivo and in vitro comparative study. Proc. Int. Symp. Somatostatin, 2nd, Athens. 107. (Abstr.)

32. Chiba, T., S. Kadowaki, T. Taminato, H. Abe, K. Chihara, S. Matsukura, Y. Goto, Y. Seino, and T. Fujita. 1981. Concentration and secretion of gastric somatostatin in streptozotocin-diabetic rats. Diabetes. 30:188-191.
33. Chiba, T., T. Taminato, S. Kadowaki, K. Chihara, S. Matsukura, M. Nozawa, Y. Seino, and T. Fujita. 1981. Reversal of increased gastric somatostatin in streptozotocin-diabetic rats by whole pancreas transplantation. Diabetes. 30:724-727.

34. Kazumi, T., M. Utsumi, G. Yoshino, K. Ishihara, Y. Hirose, H. Makimura, and S. Baba. 1980. Somatostatin concentration responds to arginine in portal plasma: effects of fasting, streptozotocin diabetes, and insulin administration in diabetic rats. Diabetes. 29:71-73.

35. Ipp, E., R. E. Dobbs, V. Harris, A. Arimura, W. Vale, and R. H. Unger. 1977. The effects of gastrin, gastric inhibitory polypeptide, secretin, and the octapeptide of cholecystokinin upon immunoreactive somatostatin release by the perfused canine pancreas. J. Clin. Invest. 60:1216-1219.

36. Kadowaki, S., T. Taminato, T. Chiba, Y. Goto, M. Nozawa, Y. Seino, S. Matsukura, and T. Fujita. 1980. Somatostatin release from the isolated, perfused diabetic rat pancreas: inverse relationship between pancreatic somatostatin and insulin. Diabetes. 29:960-963.

37. Patel, Y. C., D. P. Cameron, A. Bankier, F. Malaisse-Lagae, M. Ravazzola, P. Studer, and L. Orci. 1978. Changes in somatostatin concentration in pancreas and other tissues of streptozotocin diabetic rats. Endocrinology. 103:917-923.

38. Trimble, E. R., P. P. G. Gerber, and A. E. Renold. 1981. Abnormalities of pancreatic somatostatin secretion corrected by in vivo insulin treatment of streptozotocin-diabetic rats. Diabetes. 30:865-867.

39. Kadowaki, S., T. Taminato, T. Chiba, Y. Goto, M. Nozawa Y. Seino, S. Matsukura, and T. Fujita. 1980. Reversal of the enhanced somatostatin release from the isolated, perfused diabetic rat pancreas after the amelioration of diabetes by whole pancreas transplantation. Diabetes. 29:742-746.

40. Kawai, K., L. Orci, and R. H. Unger. 1982. High somatostatin uptake by the isolated perfused dog pancreas consistent with an insuloacinar axis. Endocrinology. 110:660-662.

41. Konturek, S. J. 1979. Current concepts of neuro-hormonal control of pancreatic secretion. Ir. J. Med. Sci. 147:1-10.

42. Lifson, N., K. G. Kramlinger, R. R. Mayrand, and E. J. Lender. 1980. Blood flow to the rabbit pancreas with special reference to the islets of Langerhans. Gastroenterology. 79:466-473.

43. Bonner-Weir, S., and L. Orci. 1982. New perspectives on the microvasculature of the islets of Langerhans in the rat. Diabetes. 31:883889. 